This item was submitted to Loughborough's Research Repository by the author.

Items in Figshare are protected by copyright, with all rights reserved, unless otherwise indicated.

\title{
Terror attacks and stock-market fluctuations: evidence based on a nonparametric causality-in-quantiles test for the $\mathrm{G} 7$ countries
}

PLEASE CITE THE PUBLISHED VERSION

http://dx.doi.org/10.1080/1351847X.2016.1239586

\section{PUBLISHER}

(C) Taylor \& Francis

\section{VERSION}

AM (Accepted Manuscript)

\section{PUBLISHER STATEMENT}

This work is made available according to the conditions of the Creative Commons Attribution-NonCommercialNoDerivatives 4.0 International (CC BY-NC-ND 4.0) licence. Full details of this licence are available at: https://creativecommons.org/licenses/by-nc-nd/4.0/

\section{LICENCE}

CC BY-NC-ND 4.0

\section{REPOSITORY RECORD}

Balcilar, Mehmet, Rangan Gupta, Christian Pierdzioch, and Mark E. Wohar. 2019. "Terror Attacks and Stockmarket Fluctuations: Evidence Based on a Nonparametric Causality-in-quantiles Test for the G7 Countries". figshare. https://hdl.handle.net/2134/26056. 


\title{
Terror Attacks and Stock-Market Fluctuations: Evidence Based on a Nonparametric Causality-in-Quantiles Test for the G7 Countries ${ }^{\#}$
}

\author{
Mehmet Balcilar $^{*}$ Rangan Gupta* ${ }^{* *}$, Christian Pierdzioch ${ }^{* * *}$ and Mark E. Wohar ${ }^{* * * *}$
}

\begin{abstract}
We use a novel non-parametric causality-in-quantiles test to study the effects of terror attacks on stock-market returns and volatility in G7 countries. We also use the novel test to study the international repercussions of terror attacks. Test results show that terror attacks often have significant effects on returns, whereas the effect on volatility is significant only for Japan and the UK for several quantiles above the median. The effects on returns in many cases become stronger in terms of significance for the upper and lower quantiles of the conditional distribution of stock-market returns. As for international repercussions, we find that terror attacks mainly affect the tails of the conditional distribution of stock-market returns. We find no evidence of a significant cross-border effects of terror attacks on stock-market volatility, where again Japan and the UK are exceptions as far as terror attacks on the US are concerned. Finally, our results continue to hold following various robustness checks involving model structure, laglengths and possible omitted variable bias.
\end{abstract}

\section{JEL classification: C22; C53; G10}

Keywords: Stock markets; returns; volatility; nonparametric causality-in-quantiles test; terror attacks; G7 countries

\footnotetext{
\# We would like to thank two anonymous referees and the Associate Editor for many helpful comments. However, any remaining errors are solely ours.

* Department of Economics, Eastern Mediterranean University, Famagusta, via Mersin 10, Northern Cyprus, Turkey and Department of Economics, University of Pretoria, Pretoria, 0002, South Africa; IPAG Business School, Paris, France. Email: mehmet@mbalcilar.net.

** Corresponding author. Department of Economics, University of Pretoria, Pretoria, 0002, South Africa. Email: rangan.gupta@up.ac.za.

*** Department of Economics, Helmut Schmidt University, Holstenhofweg 85, P.O.B. 700822, 22008 Hamburg, Germany. Email: c.pierdzioch@hsu-hh.de.

**** College of Business Administration, University of Nebraska at Omaha, 6708 Pine Street, Omaha, NE 68182, USA, and School of Business and Economics, Loughborough University, Leicestershire, LE11 3TU, UK. Email: mwohar@unomaha.edu.
} 


\section{Introduction}

Given recurrent devastating violent terror attacks and horrible bloodshed in many parts of the world, much significant empirical research has been done in recent years to document the effects of terror attacks on financial markets. Researchers have concentrated on studying three broad questions using various methodological approaches: how terror attacks affect financial-market returns, how the volatility of financial-market prices responds to terror attacks, and how shocks triggered by terror attacks transmit internationally. Our contribution to the literature on the effects of terror attacks on stock markets is that we use a novel nonparametric causality-inquantiles test recently developed by Balcilar et al. (forthcoming) to reexamine these three questions using data for the G7 countries (Canada, France, Germany, Italy, Japan, the United Kingdom (UK), and the United States (U.S.)).

The nonparametric causality-in-quantiles test combines elements of the test for nonlinear causality of k-th order developed by Nishiyama et al. (2011) with the causality-in-quantiles test developed by Jeong et al. (2012) and, hence, can be considered to be a generalization of the former. The causality-in-quantile approach has the following three novelties: Firstly, it is robust to misspecification errors as it detects the underlying dependence structure between the examined time series, which could prove to be particularly important as it is well known that stock returns display nonlinear dynamics (see Bekiros et al., forthcoming, for a detailed discussion in this regard). Secondly, via this methodology, we are able to test not only for causality-in-mean (1st moment), but also for causality that may exist in the tails of the joint distribution of the variables, which in turn, is important if the dependent variable has fat-tails something we show below to hold for stock returns. Finally, we are also able to investigate causality-in-variance and, thus, study higher-order dependencies. Such an investigation is imporant because, during some periods, causality in the conditional-mean may not exist while, at the same time, higher-order interdependencies may turn out to be significant. Moreover, it is well known that the response of stock markets is not uniform across terror attacks. Earlier researchers (Chesney et al. 2011) have found that some terror attacks trigger extreme stockmarket movements while others do not. This finding warrants a closer investigation of the effect of terror attacks across the entire conditional distribution of stock returns, something that we do in this research by means of the nonparametric causality-in-quantiles test.

Note that, nonlinear causality tests and GARCH models used in the liteature to analyze the impact of terror attacks on stock returns and/or volatility, rely on conditional-mean based 
estimation, and hence fail to capture the entire conditional distribution of stock returns and volatility - something we can do with our approach. In the process, our test is a more general procedure of detecting causality in both returns and volatility simultaneously at each point of the respective conditional distributions. Hence, we are able to capture existence or non-existence of causality at various phases (bear (lower quantiles), normal (median) and bull (upper quantiles)) of the stock markets. Being a more general test, our method is more likely to pick up causality when conditional mean-based tests might fail to do so. In addition, because we do not need decide on the number of regimes as in a Markov-switching model, and can test for causality at each point of the conditional distribution characterizing specific regimes, our test also does not suffer from any misspecification in terms of specifying and testing for the optimal the number of regimes.

Our findings can be summarized as follows: First, the effects of terror attacks on stock-market returns are significant in several cases while the effects on volatility are only significant in few cases, notably for Japan and the UK. For Japan, we find that the effect of a terror attack on the volatility of stock returns is asymmetric in the sense that the effect is stronger in terms of significance for the upper quantiles than for the lower quantiles of the distribution of stockreturn volatility. For the UK, the causality is also to some extent asymmetric, but mainly holds at certain quantiles around the median. For France, neither the effect on returns nor the effect on volatility is significant. Second, evidence of effects of terror attacks on stock-market returns becomes stronger for the lower and the upper quantiles of the conditional distribution of stockmarket returns, while the effect is insignificant in the majority of cases around the median. Hence, the strength of the significance of causality effects across quantiles can be described in terms of a u-shaped curve. Third, in terms of cross-border effects of terror attacks, we find a similar u-shaped curve for the effects of terror attacks that took place in the U.S. on stockmarket returns in the other G7 countries. Again, Japan and the UK are exceptions insofar as the effects on the volatility of stock returns are concerned, and for France all effects are insignificant for all quantiles. Fourth, further in terms of international repercussions, we find that terror attacks that originated in the other G7 countries had a significant effect on the lower and upper quantiles of the conditional distribution of U.S. stock-market returns, giving again rise to a ushaped curve that highlights the impact of such terror attacks on the tails of the conditional distribution of U.S. stock-market returns. We find no evidence of a significant effect of terror attacks in other G7 countries on U.S. stock-market volatility, consistent with results reported in earlier research. 
We structure the remainder of this research as follows. In Section 2, we review the literature on terror attacks and financial markets. In Section 3, we describe the nonparametric causality-inquantiles test. In Section 4, we describe our data and we summarize our results. In Section 5, we conclude.

\section{A Brief Literature Review}

Research on the effects of terror attacks on financial markets has made significant progress in recent years. One approach that features prominent in this strand of research is the event-study approach approach. Based on an event-study approach, Karolyi and Martell (2005) find that the effect of terror attacks on stock markets is larger when such attacks hit firms in rich and democratic countries, and that kidnapping of company executives result in larger negative stock returns than bombings of facilities or buildings. Chen and Siems (2004) use an event-study approach to show that U.S. financial markets recover quicker from the disruptions brought about by a terror attack than financial markets in several other countries. They also document that U.S. financial markets have become more resilient in recent decades with respect to terror attacks and attribute this finding to stable liquidity provision by the banking/financial sector.

Differences in the response to terror attacks across stock markets have also been reported by Kollias et al. (2011a). Upon combing an event-study approach with an analysis of GARCH models, they study the effects on general stock-market indices and across stock-market sectors of the terror attacks that took place on March11th, 2004 in Madrid and July 7th, 2005 in London. As for the general stock-market indices, they find that the London market recovered much faster than the Madrid market. They also find that returns on the day of the terror attacks were significantly negative for the majority of sectors in both markets, and that the overall effect of the terror attacks on stock-market returns and volatility was transitory (for an analysis based on forecasts of individual investors showing the expected transitory effects of the September 11 terror attacks, see Glaser and Weber 2005). Results that Kollias et al. (2011b) report based on a comparative analysis of the London and Athens stock markets using an event-study approach and GARCH models indicate that market size and maturity and specific attributes of terror attacks help to explain the differential response of stock markets to terror attacks.

Chesney et al. (2008) study the impact of several significant terror attacks on international stock markets, bond markets, and commodity markets using an event-study approach, a non- 
parametric approach, and a GARCH-based approach. They also compare the impact of terror attacks with the effects of natural disasters and financial crashes. They report that terror attacks often have a significant negative effect on stock markets, where terror attacks also affect stock markets at the industry level (e.g., indexes of the insurance and airline industries). The sign of the effect of terror attacks on gold and bond markets is leass clear-cut, showing, for example, that the hedging and safe-haven property often attributed to gold investments may not always work in the wake of terror attacks. In this regard, results that Fernandez (2008) reports are interesting. Upon using wavelet and a semi-parametric fractional autoregressive model, he finds that the volatility of an index of gold and silver significantly increased at around the beginning of the Iraq war in 2002-2003. Thereafter, volatility exhibited a trend decline. Similarly, the volatility of major stock-market indexes increased at the beginning of the Iraq war and then started declining. Trends in stock-market volatility in developing countries (in Egypt in particular), in turn, show a different pattern. Differences with regard to the response to terror attacks in terms of returns and volatility of stock returns across stock markets of developed and developing economies (Middle East and North Africa economies in particular) have also been reported by Nikkinen et al. (2008).

Drakos (2004) studies the impact of the terror attacks of September 11 on airline stocks. Based on the classic market model, he reports evidence of a structural shift in the beta factors of airline stocks, reflecting a significant increase in systematic risk. He also finds that, while idiosyncratic risk of investments in airline stocks has increased, the contribution of systematic risk to total risk has subtsantially increased. While a negative effect of terror attacks on the returns of airline stocks may reflect a deterioration of business conditions in the airline sector, results reported by Drakos (2010) suggest that psychosocial factors may also play a role for the magnitude and significance of terror attacks on stock returns. Upon studying an international panel of stock markets, he finds that terror attacks depress returns on the day of a terror attack, and that this depressing effect tends to be particularly strong for terror attacks that have a major psychosocial effect.

Focusing on terror attacks in Isreal, Eldor and Melnick (2004) find that the impact of Palestinian terror attacks on the stock market and the exchange rate in Israel did not decline over time, indicating that there is no "routine of terror attacks" (page 385). The authors study a large sample of terror attacks, and they account for the location of an attack (e.g., Jerusalem), the target type (e.g., military), and the attack type (e.g., suicide bombing). They find that suicide attacks, the number of victims injured, and the number of victims killed had a permanent effect 
on the stock market, but also that such attacks did not impair the efficient functioning of financial markets. Similarly, Johnston and Nedelescu (2005) argue that liquid and sound financial markets efficiently absorb the effects of terror attacks, but they also emphasize the key role the regulatory framework in place and the response of authorities play for mitigating the effect of a terror attack on financial markets.

Arin et al. (2008) estimate a bivariate GARCH-in-mean model on data for six different countries and find significant causal effects of terror attacks on the mean and the volatility of stock returns, where they also document that the effects of terror attacks on stock-market fluctuations in the European countries in their sample are somewhat smaller than the effects observed for the emerging market economies other countries being studied. Chuliá et al. (2007) also study a bivariate variate GARCH model. They analyze how terror attacks affect volatility transmission between the U.S. and European stock markets. They find that, while there is evidence of bidirectional volatility transmission, the terror attack that hit New York on September 11, 2001 affected volatility in European markets, whereas the terror attacks that hit London and Madrid on March 11, 2004 and July 7, 2005 did not affect the volatility of the U.S. stock market. Hon et al. (2004), in turn, use a correlation analysis and a GARCH model to show that the terror attack of September 11, 2001 led to a strong increase in the comovement of international stock markets (and that volatility did not increase). The authors conclude that market participants across the world interpreted the terror attack as an international shock. Another application of a bivariate GARCH model can be found in research by Kollias et al. (2013). They estimate bivariate vector autoregressive GARCH-in-mean models to analyze the effects of terror attacks on the returns, variance, and covariance of stock and bond returns in four European countries (France, Germany, Spain, and United Kingdom).

In terms of the overall economic effects of terrorism, Abadie und Gardeazabal (2003) show, based on data for the Basque Country, that terrorism can have quantitatively substantial economic costs. They also show that, when the 1998-1999 truce became credible, stocks of firms with intense business in the Basque Country exhibited a positive relative performance, which turned negative when it became clear that the truce would come to an end. Similarly, Barros and Gil-Alana (2009) report that terror attacks have a negative and significant effect on the returns on a Basque stock market index, while the impact of terror attacks on volatility is positive but insignificant. In order to explain theoretically large overall economic effects of terrorism, Abadie und Gardeazabal (2008) develop a continuous-time stochastic open-economy model and find that changes in the intensity of terror attacks, though their direct effect on a 
country's capital stock may be small, have the potential to trigger large cross-border movements of capital. The reason is that, in their model, terror attacks affect the expected returns on investments, implying that international investors with a low level of risk aversion abruptly change their international investment plans in response to changes in the intensity of terror attacks. They show that this effect is stronger, for a given degree of investors' risk aversion, in a globalized world economy in which the number of countries is large. The empirical evidence that they present is in line with their model. Upon using cross-country regressions and accounting for the influence of several control variables, they find that terror risk exerts a negative effect on net foreign investment positions.

\section{Testing for Causality-in-Quantiles}

We present a novel test, as proposed by Balcilar et al. (forthcoming), for the detection of nonlinear causality via a hybrid approach based on the frameworks of Nishiyama et al. (2011) and Jeong et al. (2012). As in Jeong et al. (2012), the variable $x_{t}$ (terror attacks index) does not cause $y_{t}$ (stock returns) in the $\theta$-quantile with respect to the lag-vector of $\left\{y_{t-1}, \ldots, y_{t-p}, x_{t-1}, \ldots, x_{t-p}\right\}$ if ${ }^{1}$

$$
Q_{\theta}\left(y_{t} \mid y_{t-1}, \ldots, y_{t-p}, x_{t-1}, \ldots, x_{t-p}\right)=Q_{\theta}\left(y_{t} \mid y_{t-1}, \ldots, y_{t-p}\right)
$$

$x_{t}$ causes $y_{t}$ in the $\theta$-th quantile with respect to $\left\{y_{t-1}, \ldots, y_{t-p}, x_{t-1}, \ldots, x_{t-p}\right\}$ if

$$
Q_{\theta}\left(y_{t} \mid y_{t-1}, \ldots, y_{t-p}, x_{t-1}, \ldots, x_{t-p}\right) \neq Q_{\theta}\left(y_{t} \mid y_{t-1}, \ldots, y_{t-p}\right)
$$

where $Q_{\theta}\left(y_{t} \mid \cdot\right)=\theta$-th quantile of $y_{t}$ depending on $t$ and $0<\theta<1$. In terms of notation, we let $Y_{t-1} \equiv\left(y_{t-1}, \ldots, y_{t-p}\right), X_{t-1} \equiv\left(x_{t-1}, \ldots, x_{t-p}\right)$, and $Z_{t}=\left(X_{t}, Y_{t}\right)$; and $F_{y_{t} \mid Z_{t-1}}\left(y_{t} \mid Z_{t-1}\right)$ and $F_{y_{t} \mid Y_{t-1}}\left(y_{t} \mid Y_{t-1}\right)$ denote the conditional distribution of $y_{t}$ given $Z_{t-1}$ and $Y_{t-1}$, respectively, where $F_{y_{t} \mid Y_{t-1}}\left(y_{t} \mid Y_{t-1}\right)$ is assumed to be absolutely continuous in $y_{t}$ for almost all $Z_{t-1}$. Upon defining $Q_{\theta}\left(Z_{t-1}\right) \equiv Q_{\theta}\left(y_{t} \mid Z_{t-1}\right)$ and $Q_{\theta}\left(Y_{t-1}\right) \equiv Q_{\theta}\left(y_{t} \mid Y_{t-1}\right)$, we have $F_{y_{t} \mid Z_{t-1}}\left\{Q_{\theta}\left(Z_{t-1}\right) \mid Z_{t-1}\right\}=\theta$ with probability one. Consequently, the hypotheses to be tested based on the definitions in Eqs. (1) and (2) are

$$
\begin{aligned}
& H_{0}=P\left\{F_{y_{t} \mid Z_{t-1}}\left\{Q_{\theta}\left(Y_{t-1}\right) \mid Z_{t-1}\right\}=\theta\right\}=1, \\
& H_{1}=P\left\{F_{y_{t} \mid Z_{t-1}}\left\{Q_{\theta}\left(Y_{t-1}\right) \mid Z_{t-1}\right\}=\theta\right\}<1 .
\end{aligned}
$$

\footnotetext{
${ }^{1}$ The exposition in this section closely follows Nishiyama et al. (2011) and Jeong et al. (2012).
} 
Jeong et al. (2012) use the distance measure $J=\left\{\varepsilon_{t} E\left(\varepsilon_{t} \mid Z_{t-1}\right) f_{Z}\left(Z_{t-1}\right)\right\}$, where $\varepsilon_{t}=$ regression error and $f_{Z}\left(Z_{t-1}\right)=$ marginal density function of $Z_{t-1}$. The regression error emerges based on the null in Eq. (3), which can only be true if and only if $E\left[\mathbf{1}\left\{y_{t} \leq Q_{\theta}\left(Y_{t-1}\right) \mid Z_{t-1}\right\}\right]=\theta$ or, equivalently, $\mathbf{1}\left\{y_{t} \leq Q_{\theta}\left(Y_{t-1}\right)\right\}=\theta+\varepsilon_{t}$, where $\mathbf{1}\{\cdot\}=$ indicator function. Jeong et al. (2012) specify the distance measure, $J \geq 0$, as follows:

$$
J=E\left[\left\{F_{y_{t} \mid Z_{t-1}}\left\{Q_{\theta}\left(Y_{t-1}\right) \mid Z_{t-1}\right\}-\theta\right\}^{2} f_{Z}\left(Z_{t-1}\right)\right]
$$

We have $J=0$ if and only if $H_{0}$ in Eq. (3) is true, while $J>0$ holds under $H_{1}$ in Eq. (4). Jeong et al. (2012) show that the feasible kernel-based test statistic for $J$ has the following form:

$$
\hat{J}_{T}=\frac{1}{T(T-1) h^{2 p}} \sum_{t=p+1}^{T} \sum_{s=p+1, s \neq t}^{T} K\left(\frac{Z_{t-1}-Z_{S-1}}{h}\right) \hat{\varepsilon}_{t} \hat{\varepsilon}_{s}
$$

where $K(\cdot)=$ kernel function with bandwidth $h, T=$ sample size, $p=$ lag-order, and $\hat{\varepsilon}_{t}=$ estimate of the regression error, computed as

$$
\hat{\varepsilon}_{t}=\mathbf{1}\left\{y_{t} \leq \hat{Q}_{\theta}\left(Y_{t-1}\right)\right\}-\theta
$$

We use a nonparametric kernel method to estimate the $\theta$-th conditional quantile of $y_{t}$ given $Y_{t-1}$ as $\hat{Q}_{\theta}\left(Y_{t-1}\right)=\hat{F}_{y_{t} \mid Y_{t-1}}^{-1}\left(\theta \mid Y_{t-1}\right)$, where $\hat{F}_{y_{t} \mid Y_{t-1}}\left(y_{t} \mid Y_{t-1}\right)=$ Nadarya-Watson kernel estimator:

$$
\widehat{F}_{y_{t} \mid Y_{t-1}}\left(y_{t} \mid Y_{t-1}\right)=\frac{\sum_{S=p+1, S \neq t}^{T} L\left(\frac{Y_{t-1}-Y_{S-1}}{h}\right) \mathbf{1}\left(y_{s} \leq y_{t}\right)}{\sum_{s=p+1, S \neq t}^{T} L\left(\frac{Y_{t-1}-Y_{S-1}}{h}\right)},
$$

with $L(\cdot)=$ the kernel function and $h$ the bandwidth.

In an extension of the Jeong et al. (2012) framework, we develop a test for the 2nd moment. To this end, we use the nonparametric Granger-quantile-causality approach by Nishiyama et al. (2011). In order to illustrate the causality in higher order moments, we assume

$$
y_{t}=g\left(Y_{t-1}\right)+\sigma\left(X_{t-1}\right) \varepsilon_{t}
$$

where $\varepsilon_{t}=$ white noise process, and $g(\cdot)$ and $\sigma(\cdot)=$ unknown functions that satisfy certain conditions for stationarity. This specification does not allow for Granger-type causality testing from $X_{t-1}$ to $y_{t}$, but could possibly detect the "predictive power" from $X_{t-1}$ to $y_{t}^{2}$ when $\sigma(\cdot)$ is a general nonlinear function. Hence, the Granger causality-in-variance definition does not require an explicit specification of squares for $X_{t-1}$. We re-formulate Eq. (9) into a null and alternative hypothesis for causality in variance as follows: 


$$
\begin{aligned}
& H_{0}=P\left\{F_{y_{t}^{2} \mid Z_{t-1}}\left\{Q_{\theta}\left(Y_{t-1}\right) \mid Z_{t-1}\right\}=\theta\right\}=1, \\
& H_{1}=P\left\{F_{y_{t}^{2} \mid Z_{t-1}}\left\{Q_{\theta}\left(Y_{t-1}\right) \mid Z_{t-1}\right\}=\theta\right\}<1 .
\end{aligned}
$$

To obtain a feasible test statistic for testing the null hypothesis in Eq. (10), we replace $y_{t}$ in Eq. (6) - (8) with $y_{t}^{2}$ (squared stock returns, i.e., volatility). Incorporating the Jeong et al. (2012) approach, we overcome the problem that causality in the conditional 1st moment (mean) imply causality in the 2nd moment (variance). Specifically, we interpret the causality in higher-order moments using the following model:

$$
y_{t}=g\left(X_{t-1}, Y_{t-1}\right)+\epsilon_{t}
$$

Thus, higher order quantile causality can be specified as:

$$
\begin{gathered}
H_{0}=P\left\{F_{y_{t}^{k} \mid Z_{t-1}}\left\{Q_{\theta}\left(Y_{t-1}\right) \mid Z_{t-1}\right\}=\theta\right\}=1 \quad \text { for } k=1,2, \ldots, K, \\
H_{1}=P\left\{F_{y_{t}^{k} \mid Z_{t-1}}\left\{Q_{\theta}\left(Y_{t-1}\right) \mid Z_{t-1}\right\}=\theta\right\}<1 \quad \text { for } k=1,2, \ldots, K .
\end{gathered}
$$

Integrating the entire framework, we define that $x_{t}$ Granger causes $y_{t}$ in quantile $\theta$ up to the $K$-th moment utilizing Eq. (13) to construct the test statistic of Eq. (6) for each $k$. However, it can be shown that it is not easy to combine the different statistics for each $k=1,2, \ldots, K$ into one statistic for the joint null in Eq. (13) because the statistics are mutually correlated (Nishiyama et al. 2011). To efficiently address this issue, we include a sequential-testing method as described by Nishiyama et al. (2011) with some modifications. Firstly, we test for nonparametric Granger causality in the 1 st moment $(k=1)$. Failure to reject the null for $k=1$, does not automatically lead to noncausality in the 2 nd moment and, thus, we construct the tests for $k=2$. Finally, we test for the existence of causality-in-variance, or the causality-in-mean and variance successively.

The empirical implementation of the causality-in-quantiles test requires specifying the bandwidth $h$, the lag order $p$, and the kernel type for $K(\cdot)$ and $L(\cdot)$ in Eq. (6) and (8). We determine the lag 
order using the Schwarz Information Criterion (SIC). ${ }^{2}$ The bandwidth is selected using the least squares cross-validation method. For $K(\cdot)$ and $L(\cdot)$, we use Gaussian kernels.

\section{Data and empirical results}

\subsection{Data}

Our analysis is based on two daily variables: stock-market returns and an index of terror attacks for the G7 (Canada, France, Germany, Italy, Japan, UK, and U.S.) countries. Using stock-market returns ensures that the dependent variable is stationary - a requirement for our causality analysis. ${ }^{3}$ The terror index (discussed below) is stationary by design. Stock-market returns are measured in terms of the first-differenced of the natural log of the stock-market index of each of the G7 countries, where we obtained the data on the stock-market indexes from Bloomberg. Like Eckstein and Tsiddon (2004) and Arin et al., (2008), the daily terror index is defined as the natural logarithm of (e+number of human casualties+number of people injured + number of terrorist attacks), that occurred each day and where $e$ denotes the exponential function. As in Arin et al., (2008), terror attacks which occurred during a weekend were summed up to the previous Friday's figure. ${ }^{4}$ Data on the terror attacks were collected from the RAND Database of Worldwide Terrorism Incidents (RDWTI) ${ }^{5}$ and the Global Terrorism Database (GTD) ${ }^{6}$. The RDWTI and GTD integrate data from many important terrorism resources. Figure 1 displays the stockmarket indexes and the data on terror attacks and Table 1 shows some summary statistics of the data. As can be seen, both variables are non-normal with heavy tails, which, in turn, provides some preliminary justification for using the causality-in-quantiles test.

-- Please insert Figure 1 and Table 1 about here. --

Given data availability on stock-market indexes and terror indexes, with the former driving the start date and the latter the end date of our samples, our samples cover the following periods after matching the dates of the two variables, Canada: $3^{\text {rd }}$, January, 1977 to $31^{\text {st }}$ December, 2014 (9,566 observations); France: $10^{\text {th }}$, July, 1987 to $31^{\text {st }}$ December, 2014 (6,950 observations);

\footnotetext{
2 The SIC is known to select a parsimonious number of lags and, thereby, prevents overparameterization problems associated with nonparametric approaches. Hurvich and Tsai (1989) examine the Akaike Information Criterion (AIC) and show that it is biased towards selecting an overparameterized model, while the SIC is asymptotically consistent. A lag-length of one was chosen in all cases, which, in turn, is consistent with the standard predictive regression framework used to predict stock returns (Rapach and Zhou, 2013).

${ }^{3}$ Details of the unit-root tests are available upon request from the authors.

4 This equation means that the index takes a value of 1 on days when there are no terror attacks. We follow the papers by Eckstein and Tsiddon (2004) and Arin et al., (2008) in this regard.

5 Available freely for download from: http://www.rand.org/nsrd/projects/terrorism-incidents.html.

${ }^{6}$ Available freely for download from: https://www.start.umd.edu/gtd/.
} 
Germany: $23^{\text {rd }}$, February, 1968 to $31^{\text {st }}$ December, 2014 (11,785 observations); Italy: $2^{\text {nd }}$, January, 1998 to $31^{\text {st }}$ December, 2014 (4,311 observations); Japan: $6^{\text {th }}$, January, 1970 to $31^{\text {st }}$ December, 2014 (11,095 observations); UK: $3^{\text {rd }}$, January, 1984 to $31^{\text {st }}$ December, 2014 (7,848 observations) and; US: $26^{\text {th }}$, February, 1968 to $31^{\text {st }}$ December, 2014 (11,795 observations).

\subsection{Main Results}

Our analysis comes in three parts: We study (i) the impact of the terror index of a country on stock-market returns and volatility of that country, (ii) the impact of terror attacks on the U.S. on stock-market returns and volatility of the other G7 countries (Canada, France, Germany, Italy, Japan, and UK) countries, and, (iii) the impact of terror attacks on Canada, France, Germany, Italy, Japan, and the UK on U.S. stock-market returns and volatility. ${ }^{7}$ Because the data on terror attacks start on $21^{\text {st }}$ February, 1968, the analysis of the third part of the analysis starts on the starting date of the U.S. data. For the other two parts, the sample period covered are as discussed in the preceding paragraph. ${ }^{8}$

-- Please insert Figure 2 about here. --

Figure 2 summarizes the results of the non-parametric causality-in-quantiles tests when we regress a countries stock-market returns / volatility on the terror index of that country. The horizontal axis shows the quantiles and the vertical axis shows the test results. The grey horizontal line represents the $95 \%$ critical value. The bright solid line represents the results for stock-market returns and the dark dashed line represents the results for volatility. For Canada, Germany, Italy, the UK, and the U.S., the solid thick line for stock-market returns has a characteristic u-shaped pattern, implying that the evidence of significant causal effects of terror attacks becomes stronger in the tails of the conditional distribution of stock-market returns. While for Germany the effect of terror attacks is significant also for quantiles around the median

\footnotetext{
7 To motivate the quantile-based model from a statistical perspective, we also conducted the Koenker and Bassett's (1982) test of slope homogeneity, and the null of equality of slopes across the quantiles were overwhelmingly rejected in all cases at the highest level of significance. Complete details of these results are available upon request from the authors.

8 As a starting point, we also conducted linear Granger-noncausality tests for the three parts of our analysis. However, we were not able to detect any predictability running from the terror indices to stock-market returns in any of three parts, possibly due to a misspecification of the linear model. When we applied the Brock et al., (1996, BDS) test to the residuals of the equation linking linking stock-market returns to the terror index, the null hypothesis of ïd residuals was rejected, implying evidence of uncaptured nonlinearity between these two variables. In addition, the Andrews (1993) and Andrews and Ploberger (1994) tests (Sup-F, Exp-F and Mean-F) of parameter instability (break point) rejected the null hypothesis of stability in all equations. The results from the nonlinearity and parameter-stability tests show that it is worthwhile to use a nonlinear approach to study causality, which is what we do via the causality-in-quantiles test. Complete details of the standard Granger causality, the BDS, and Andrews (1993), and Andrews and Ploberger (1994) tests are available upon request from the authors.
} 
of the conditional distribution of stock-market returns, the effects become significant only for the lower and upper quantiles in the cases of the other countries. For France, we observe no significant causal effect, irrespective of whether we study stock-market returns or volatility. For Japan, in turn, we observe significant causal effects of terror attacks only on volatility but not on stock-market returns. Moreover, the causal effects on volatility are asymmetric because they are significant for the upper quantiles of the conditional distribution of volatility and insignificant for the lower quantiles. For the UK, causality in volatility holds at certain quantiles around the median. None of the remaining five countries show any evidence of volatility predictability emanating from terror attacks.

-- Please insert Figure 3 about here. --

Figure 3 summarizes the results of the non-parametric causality-in-quantiles tests when we regress a countries stock-market returns / volatility on the U.S. terror index. For Canada, Germany, Italy, and the UK, there is strong evidence of significant causal cross-border effects of U.S. terror attacks onto the lower and upper quantiles of the conditional distribution of stockmarket returns. The stock market of France, in turn, seems to be largely insulated from U.S. terror attacks. In terms of volatility, there is evidence of a causal international spillover effect only in the case of Japan and the UK at several quantile above the median primarily.

-- Please insert Figure 4 about here. --

Figure 4 summarizes the results of the non-parametric causality-in-quantiles tests when we regress U.S. stock-market returns / volatility on the terror indexes of the other G7 countries. The results are very similar across countries. The results show that there is no evidence of international repercussions as far as volatility is concerned. For stock-market returns, in turn, we observe the characteristic u-shaped curve similar to the curve that we already found in the other parts of our empirical analysis.

\subsection{Robustness Checks}

Based on the suggestions of two anonymous referees, we conducted the following robustness checks:

(i) We conducted the nonlinear test of causality developed by Diks and Panchenko (2005) on the returns, as well as a GARCH model estimation. The GARCH model showed no evidence of the lagged terror index in causing either returns or volatility 
for all the cases under the three scenarios discussed above. The Diks and Panchenko (2005) test detected some evidence of causality in returns, highlighting the importance of nonlinearity missed by the GARCH model. Specifically, we find causality for Germany and US only under the case of own terror attacks on own stock returns (compared to quantile causality at certain quantiles for all cases except France), causality in all cases except Japan when it comes to terror attacks in these countries causing US stock returns (compared to quantile causality at certain quantiles for all cases), and US terror attacks only causing Canadian stock returns (compared to quantile causality at certain quantiles for all cases except France). In light of relatively weaker evidence obtained from the Diks and Panchenko (2005) test and the GARCH model compared to our causality-in-quantiles test, and these models being less informative based on conditional-mean (and hence, unable to capture market phases), these results have not been formally reported in the paper to save space. However, complete details of these results are available upon request from the authors;

(ii) We use the Akaike Information Criterion (AIC) rather than the SIC to choose our lag-length. In general, there were virtually no differences in our results compared to those under the SIC. A couple of exceptions related with Japan involved causality being observed now due to own terror attacks, and US terror attacks under the AIC. Also, the effect of G6 terror attacks on US returns seemed to be stronger under the SIC, though causal structure was unaffected, suggesting that the effect of terror attacks tends to die down at longer lags picked up by the AIC. Complete details of these results are available upon request from the authors, and have not been reported to save space;

(iii) We estimated univariate GARCH models as a measure of conditional volatility and used it instead of the squared returns as a measure of volatility. In general, results are similar across squared returns and the GARCH-based estimate of conditional volatility. The major difference was with US stock returns volatility measured using the GARCH model showed the presence of causality due to G6 terror attacks over the entire quantile range considered, which was not picked up by squared returns. Also, the causal relationships for Japan and UK due to own terror attacks and US terror attacks based on the GARCH-estimated measure of volatility was stronger (covered the entire quantile range) compared to the corresponding cases with 
squared returns. We believe that because squared returns as a measure of volatility follows directly from the $k$-th order test and is independent of a model-based estimate of volatility (which could vary depending on what model we choose), the use of squared returns is more appropriate in our context. Hence, the formal discussion of the the recovered conditional volatility from univariate GARCH models have been avoided here to prevent extending the length of the paper, but these results are available upon request from the authors;

(iv) Finally, to accommodate for the possibility of an important omitted variable like the VIX, we undertook an indirect approach of testing the robustness of our causalityin-quantiles test. Unlike linear test of causality, which can be multivariate, all known nonlinear tests of causality are in fact bivariate (see for example, Heimstra and Jones (1994), Diks and Panchenko (2005), Nishiyama et al., (2011), Jeong et al., (2011)). Our indirect approach involves two steps: First, we estimate a linear causality model with VIX only in the regression; and second, recover the residuals from this model and apply our nonparametric causality-in-quantiles test on these residuals. So, the idea here is to create a filtered series for the stock returns, whose movements are now no longer due to the VIX. Note that, using the VIX implies that we can start only in 1986 at the earliest, with the data sourced from the FRED database of the Federal Reserve Bank of St. Louis. ${ }^{9}$ We observed that, whether we use the actual returns series or the filtered series (errors), results are qualitatively similar, suggesting that incorporating (indirectly) the information from the VIX does not tend to affect our causal relationship obtained for stock returns and volatility. However, there are couple of exceptions when analysing own-country terror attacks and US terror attacks: causality for stock returns of Germany (Japan) is lost (gained) when we consider the filtered series instead of actual stock returns. In addition, when we compare our original set of results obtained under the longer samples for Canada, Germany, Japan, UK and the US, we again tend to see the impact of terror attacks is primarily concentrated in causing returns rather than volatility. Since our results are virtually unchanged with the indirect inclusion of the VIX, these have not been formally reported in the paper to save space, but are available upon request from the authors.

\footnotetext{
${ }^{9}$ Prior to 1990 , i.e., when the VIX data starts, we merge the VXO data to start in 1986.
} 


\section{Concluding remarks}

The results we have reported in this research contribute to the growing literature on the effects of terror attacks on financial markets. We have contributed to this research by using a novel nonparametric causality-in-quantiles test to inspect the effect of terror attacks on the quantiles of the conditional distribution of stock-market returns and volatility, both at a national and at an international level. We have found strong evidence of causality for stock-market returns, with the exceptions of France and Japan. We further have found that the evidence in favour of the causal effect of terror attacks tends to become stronger for the lower and the upper quantiles of the conditional distribution of stock-market returns. We have found evidence that terror attacks (at home or on the U.S.) move volatility only for Japan and the UK at several quantiles mainyl above the median. In addition, we also found that our results continue to hold for various robustness checks involving other tests like nonlinear causality and GARCH models, longer lag-lengths, alternative measure of variance and possible omitted variables like the VIX.

Our results have important implications given that stock-market return and volatility (often interpreted as a measure of uncertainty) are among the most important indicators for capital budgeting and portfolio-management decisions because they directly reflect how market participants assess companies' financial health and future prospects (Poon and Granger, 2003; Rapach and Zhou, 2013). Our results indicate that terror attacks can predict stock-market returns in many cases mainly during strong bear and bull-periods as defined in terms of returns drawn from tails of the conditional distribution of stock returns. At the same time, terror attacks have no significant predictive value for uncertainty (that is, volatility measured in terms of squared returns) in the stock market of G7 countries, with Japan and the UK being notable exceptions. As an avenue of future research, it would be interesting to extend our analysis to a forecasting model because in-sample predictability does not necessarily guarantee predictability over an outof-sample period (Rapach and Zhou, 2013). 


\section{References}

Abadie, A., Gardeazabal, J. (2003). The economic cost of conflict: A case study of the Basque country, American Economic Review, 93, 113-132.

Abadie, A., Gardeazabal, J. (2008). Terrorism and the world economy, European Economic Review, 52, 1-27.

Andrews, D.W.K. (1993). Tests for parameter instability and structural change with unknown change point, Econometrica, 61, 821-856.

Andrews, D.W.K. and Ploberger, W. (1994). Optimal tests when a nuisance parameter is present only under the alternative, Econometrica, 62, 1383-1414.

Arin, K.P., Ciferri, D., and Spagnolo, N., 2008. The price of terror: The effects of terrorism on stock market returns and volatility. Economics Letters 101, 164-167.

Balcilar, M., Bekiros, S., and Gupta, R. (Forthcoming). The role of news-based uncertainty indices in predicting oil markets: a hybrid nonparametric quantile causality method, Empirical Economics.

Barros, C.P., Gil-Alana, L. (2008). Stock market returns and terrorist violence: evidence from the Basque Country, Applied Economics Letters, 16, 1575-1579.

Bekiros, S., Gupta, R., and Majumdar, A., (Forthcoming). Incorporating Economic Policy Uncertainty in US Equity Premium Models: A Nonlinear Predictability Analysis. Finance Research Letters.

Brock, W., Dechert, D., Scheinkman, J. and LeBaron, B. (1996). A test for independence based on the correlation dimension. Econometric Reviews, 15, 197-235.

Chen, A.H., and Siems, T.F., 2004. The effects of terrorism on global capital markets. European Journal of Political Economy 20, 349-366.

Chesney, M., Reshetar, G., Karaman, M. (2011). The impact of terrorism on financial markets: an empirical study, Journal of Banking and Finance, 35, 253-267.

Chuliá, H., Climent, F.J., Soriano, P., and Torró, H., 2009. Volatility transmission patterns and terrorist attacks. Quantitative Finance 9 (5), 607-619. 
Drakos, K. (2004). Terrorism-induced structural shifts in financial risk: airline stocks in the aftermath of the September 11th terror attacks, European Journal of Political Economy, 20, 435-446.

Drakos, K. (2010). Terrorism activity, investor sentiment and stock returns, Review of Financial Economics, 19, 128-135.

Eldor, R.,and Melnick, R., 2004. Financial markets and terrorism. European Journal of Political Economy 20, 367-386.

Fernandez, V. (2008). The war on terror and its impact on the long term volatility of financial markets, International Review of Financial Analysis, 17, 1-26.

Glaser, M., and Weber, M. (2005). September 11 and stock return expectations of individual investors, Review of Finance, 9. 243-279.

Hiemstra, C. and Jones, J. D. (1994). Testing for linear and nonlinear Granger causality in the stock price-volume relation. Journal of Finance, 49, number 5, 1639-1664.

Hon, M.T., Strauss, J., and Yong, S.-Y., 2004. Contagion in financial markets after September 11: myth or reality? Journal of Financial Research 27: 95-114.

Hurvich, C.M. and Tsai, C.-L. (1989). Regression and Time Series Model Selection in Small Samples. Biometrika, 76, 297-307.

Jeong, K., Härdle, W. K. and Song, S., 2012. A consistent nonparametric test for causality in quantile. Econometric Theory 28, 861-887.

Johnston, B., and O. Nedelescu, 2006. The impact of terrorism on financial markets. Journal of Financial Crime 13: 7-25.

Karolyi, A., and Martell, R., 2010. Terrorism and the stock market. International Review of Applied Financial Issues and Economics 2: 285-314.

Koenker, R.W. and Bassett Jr., G.S. (1982), Robust Tests for Heteroscedasticity Based on Regression Quantiles, Econometrica, 50, 43-61.

Kollias, C., Papadamou, S., and Stagiannis, A. (2011a). Terrorism and capital markets: the effects of the Madrid and London bomb attacks, International Review of Economics and Finance, 20, $532-541$. 
Kollias, C., Papadamou, S., and Stagiannis, A. (2011b). Stock markets and terrorist attacks: comparative evidence from a large and a small capitalization market, European Journal of Political Economy, 27, S64-S77.

Kollias, C., Papadamou, S., and Arvanitis, V. (2013a). Does terrorism affect the stockbond covariance? Evidence from European countries, Southern Economic Journal, 79, 832-548.

Nikkinen, J., Omran, M., Sahlstrom, P., Aijo, J. (2008). Stock returns and volatility following the September 11 attacks: Evidence from 53 equity markets, International Review of Financial Analysis, 17, 27-46.

Nishiyama, Y., Hitomi, K., Kawasaki, Y., and Jeong, K., 2011. A consistent nonparametric Test for nonlinear causality - specification in time series regression. Journal of Econometrics 165, $112-127$.

Poon, W. C., and Tong, G. K. 2010. Output growth, inflation and interest rate on stock return and volatility: the predictive power. SSRN Working Paper No. 1605883.

Rapach, D., and G. Zhou. 2013. Forecasting Stock Returns: in Handbook of Economic Forecasting, Volume 2A, Graham Elliott and Allan Timmermann (Eds.) Amsterdam: Elsevier, $328-383$. 
Figure 1a. G7 Stock Returns

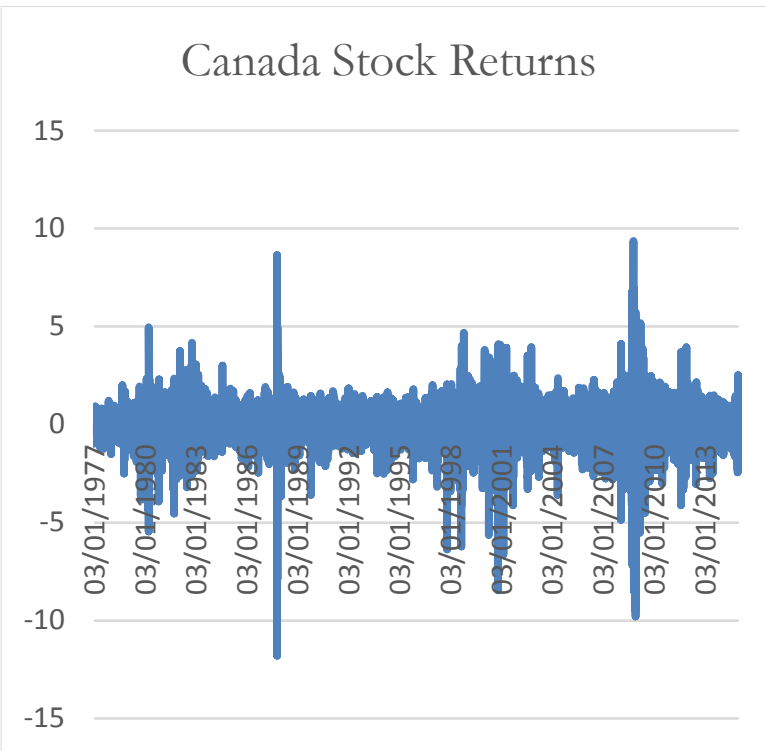

Germany Stock Returns

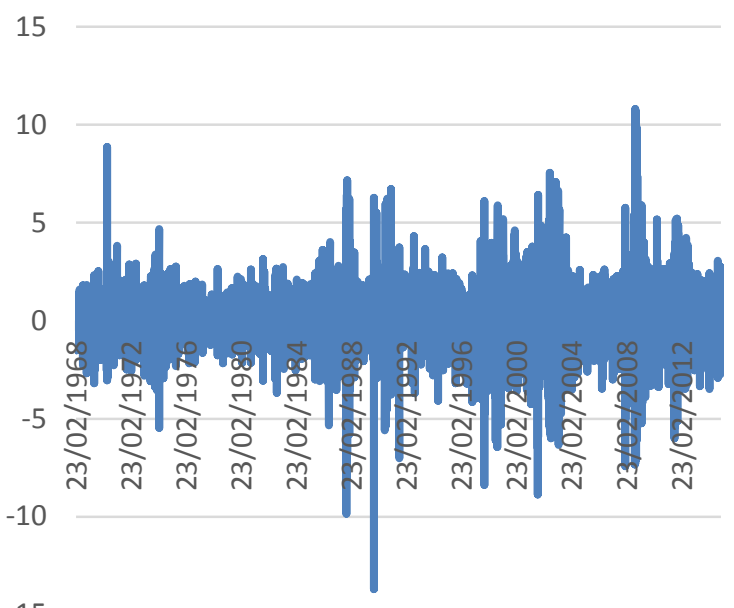

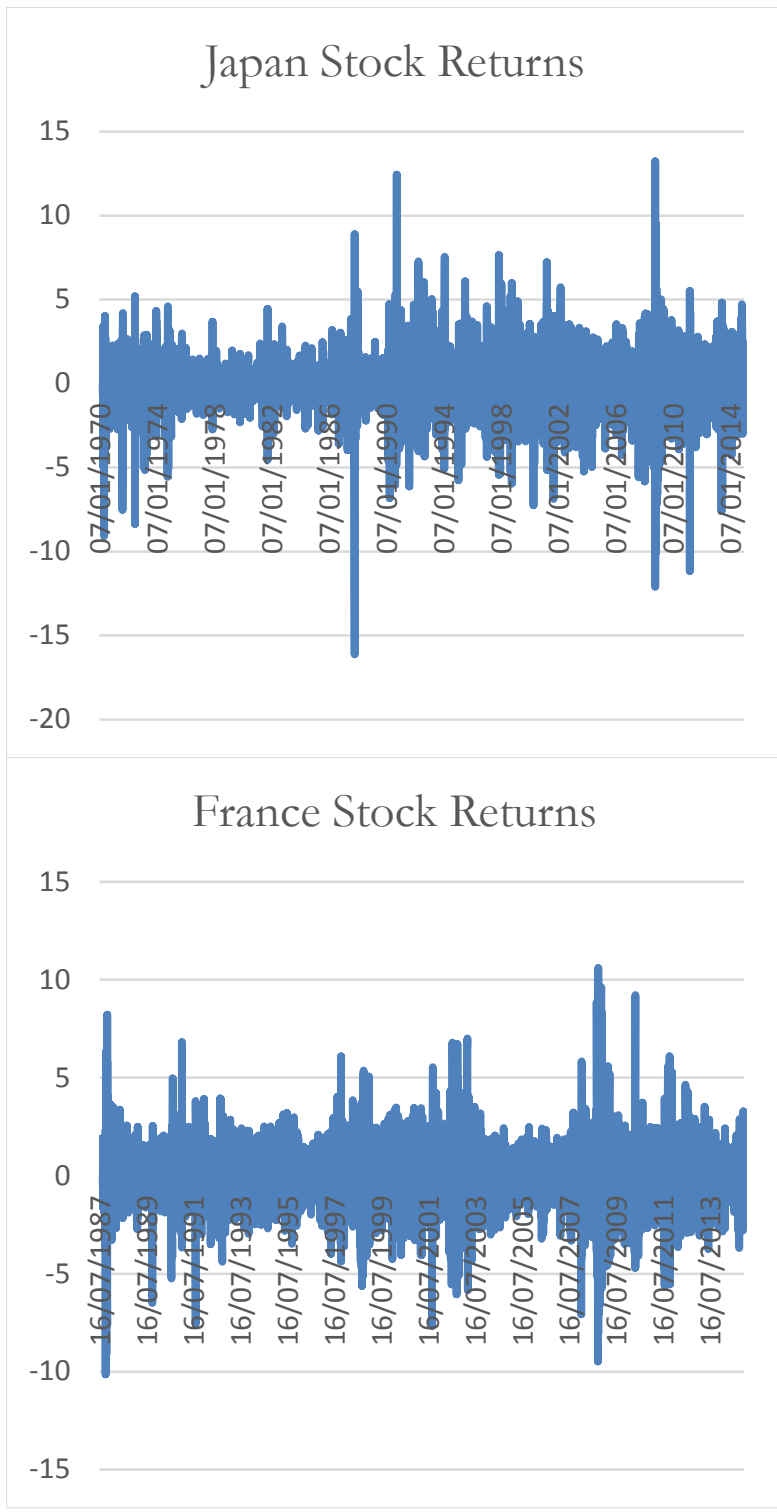



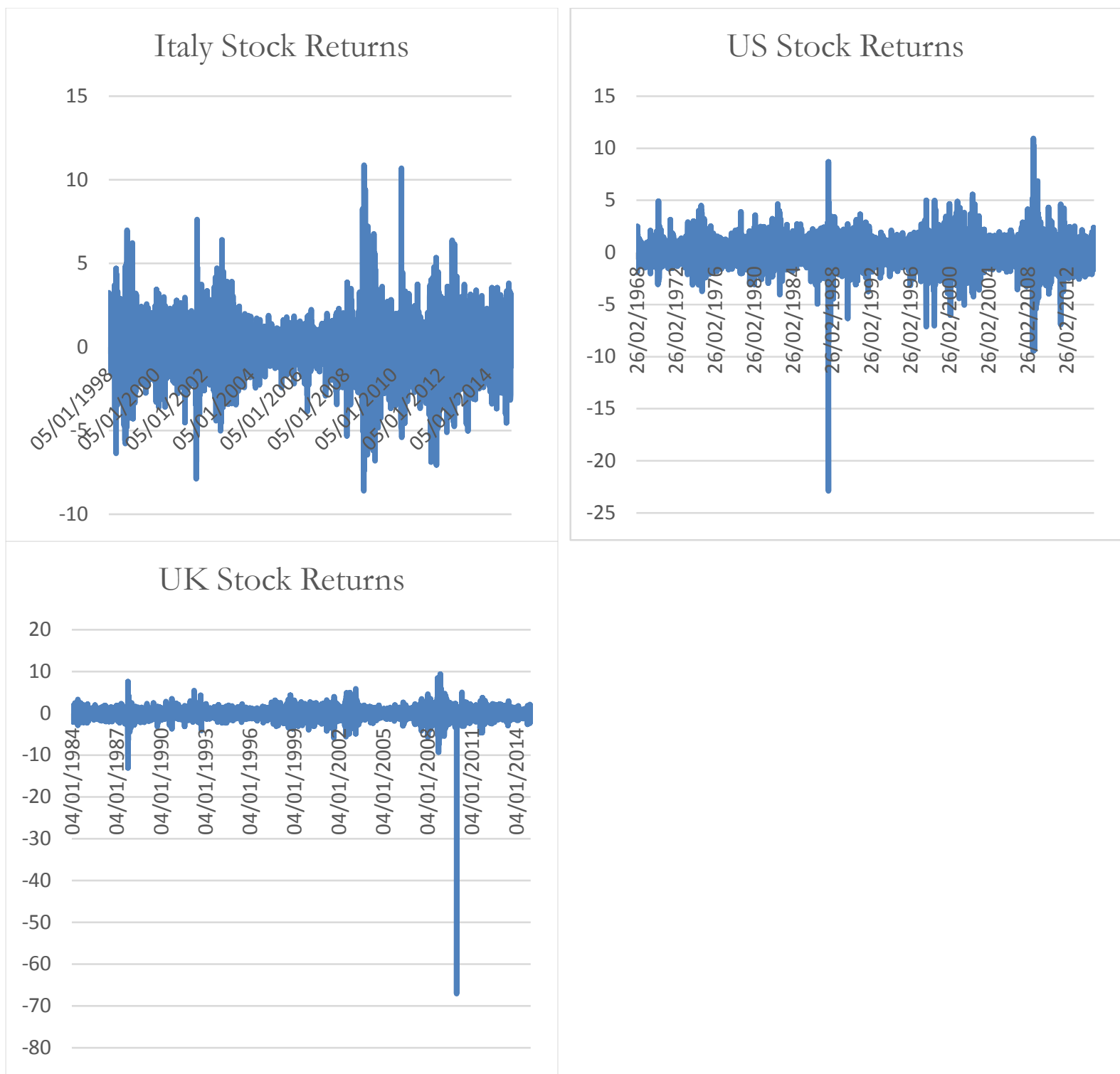
Figure 1b. G7 Terror Index

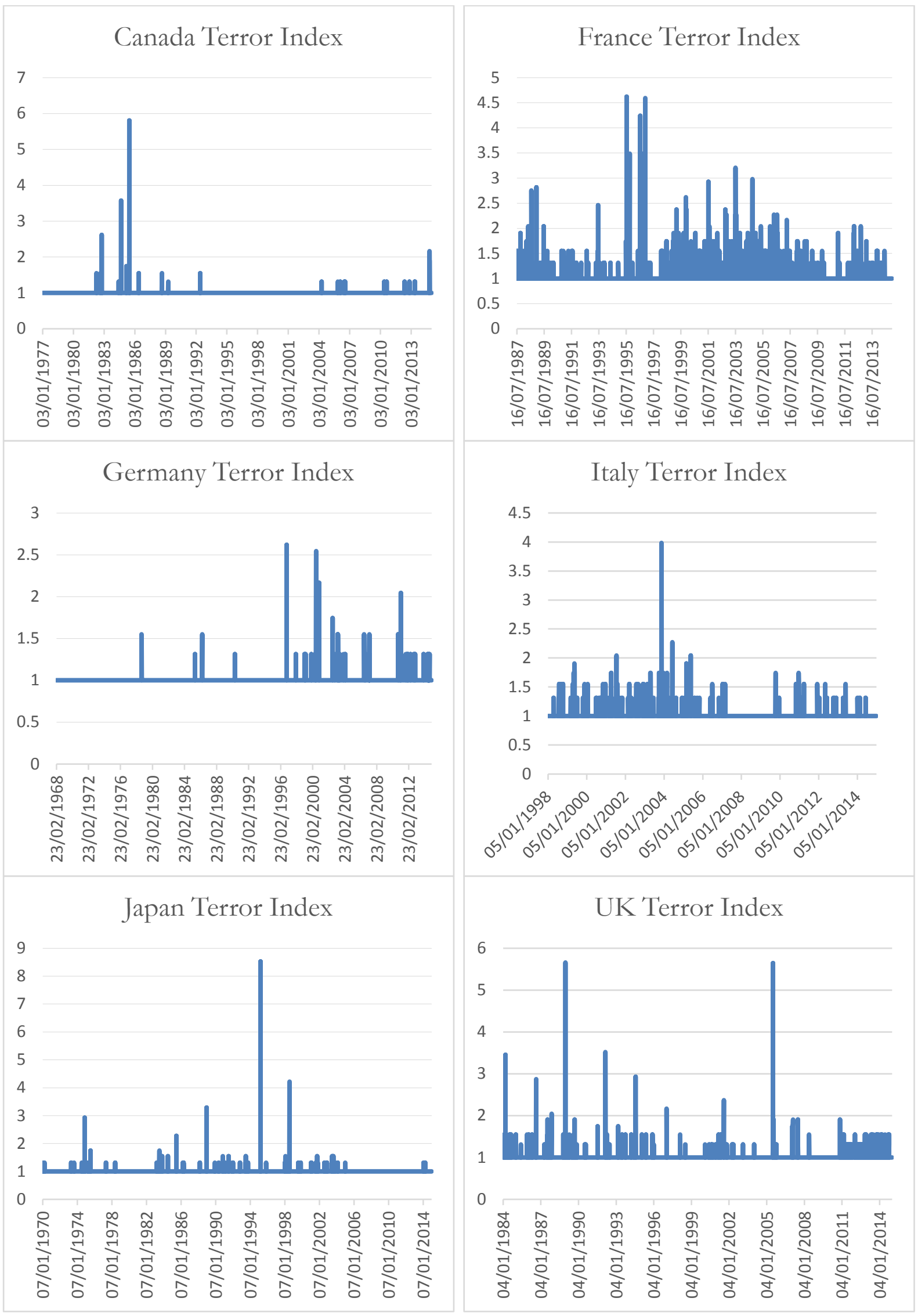




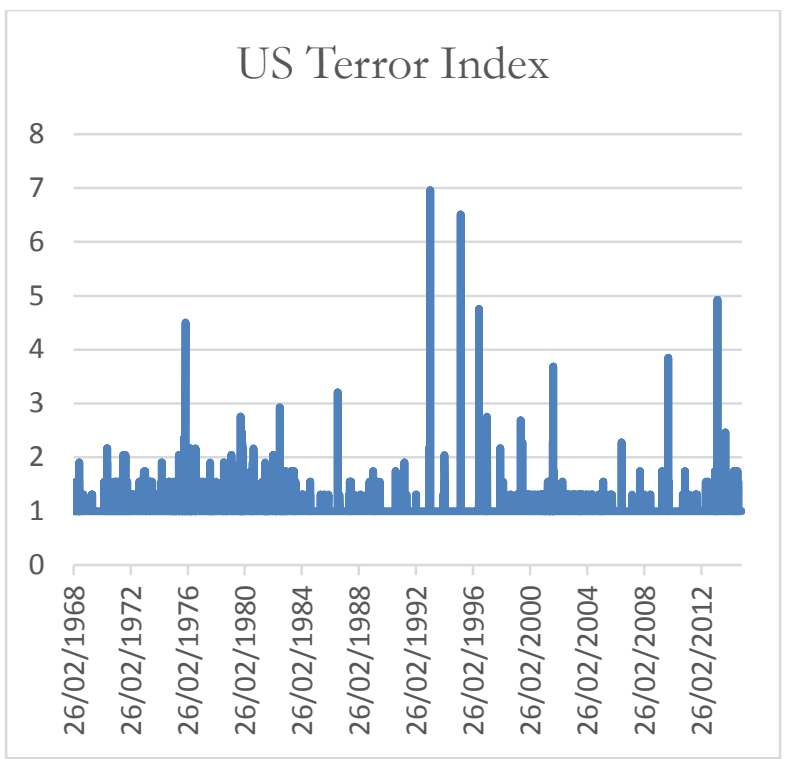


Table 1. Summary Statistics

\begin{tabular}{|l|r|r|r|r|r|r|r|}
\hline & \multicolumn{7}{|c|}{ Stock Returns } \\
\hline & Canada & \multicolumn{1}{|c|}{ France } & Germany & \multicolumn{1}{c|}{ Italy } & \multicolumn{1}{c|}{ Japan } & \multicolumn{1}{c|}{ UK } & \multicolumn{1}{c|}{ US } \\
\hline Mean & 0.028 & 0.015 & 0.025 & -0.006 & 0.018 & 0.016 & 0.026 \\
\hline Std. Dev. & 0.955 & 1.403 & 1.257 & 1.566 & 1.299 & 1.338 & 1.062 \\
\hline Skewness & -0.886 & -0.141 & -0.247 & -0.074 & -0.425 & -16.317 & -1.019 \\
\hline Kurtosis & 16.760 & 8.293 & 10.140 & 6.905 & 12.677 & 810.363 & 29.123 \\
\hline Jarque-Bera & 76715.98 & 8135.22 & 25153.05 & 2743.42 & 43628.56 & 213000000.0 & 337407.30 \\
\hline Probability & 0.000 & 0.000 & 0.000 & 0.0000 & 0.000 & 0.000 & 0.000 \\
\hline & \multicolumn{7}{|c|}{ Terror Index } \\
\hline Mean & 1.002 & 1.041 & 1.002 & 1.017 & 1.004 & 1.016 & 1.020 \\
\hline Std. Dev. & 0.063 & 0.172 & 0.034 & 0.100 & 0.089 & 0.118 & 0.146 \\
\hline Skewness & 57.187 & 8.262 & 29.355 & 10.646 & 62.741 & 20.875 & 18.646 \\
\hline Kurtosis & 3920.672 & 113.110 & 1110.038 & 214.717 & 4905.802 & 687.740 & 557.428 \\
\hline Jarque-Bera & $6.12 \mathrm{E}+09$ & 3590049 & $6.03 \mathrm{E}+08$ & 8132931 & $1.11 \mathrm{E}+10$ & $1.54 \mathrm{E}+08$ & $1.52 \mathrm{E}+08$ \\
\hline Probability & 0.000 & 0.000 & 0.000 & 0.000 & 0.000 & 0.000 & 0.000 \\
\hline & 9566 & 6950 & 11785 & 4311 & 11095 & 7848 & 11795 \\
\hline
\end{tabular}

Note: Std. Dev stands for standard deviation; Probability indicates the probability of the null hypothesis of normality corresponding to the Jarque-Bera statistic. 
Figure 2: Individual Effect of Terror Attacks on G7 Stock Returns
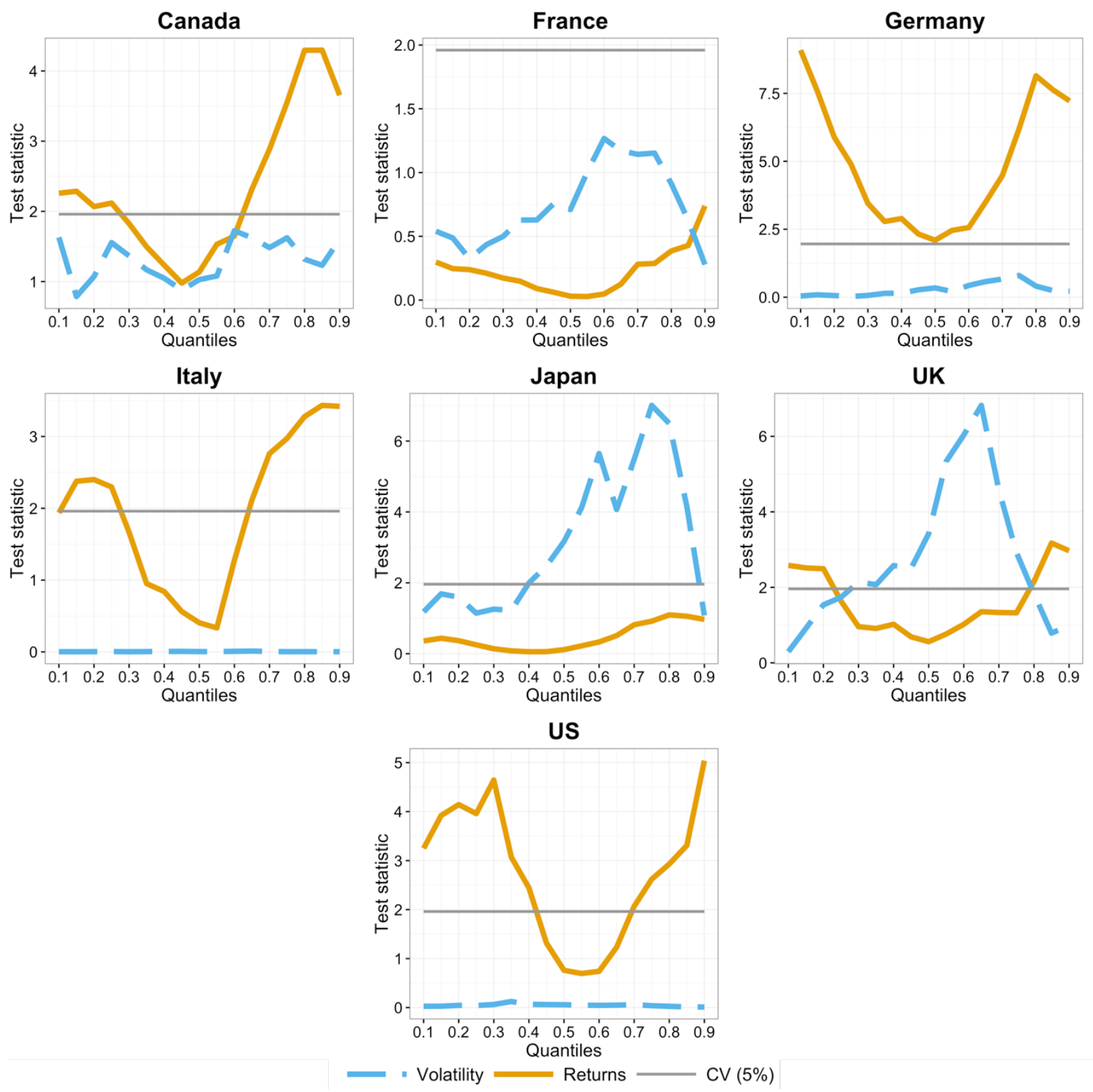
Figure 3: Effect of Terror Attacks on the US on the Stock Returns of the other G7 Countries
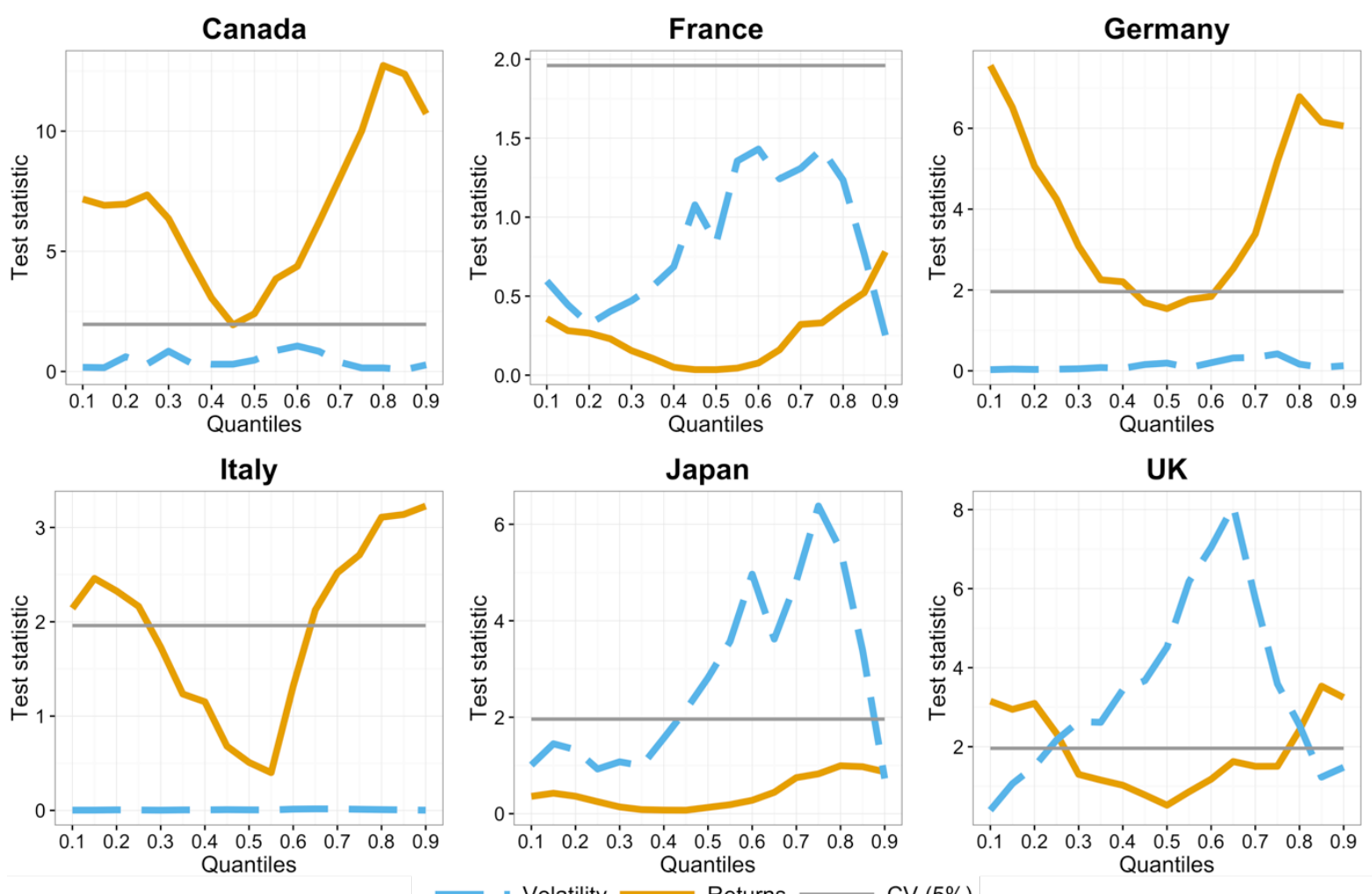
Figure 4: Effect of Terror Attacks on the other G7 countries on the Stock Returns of the US
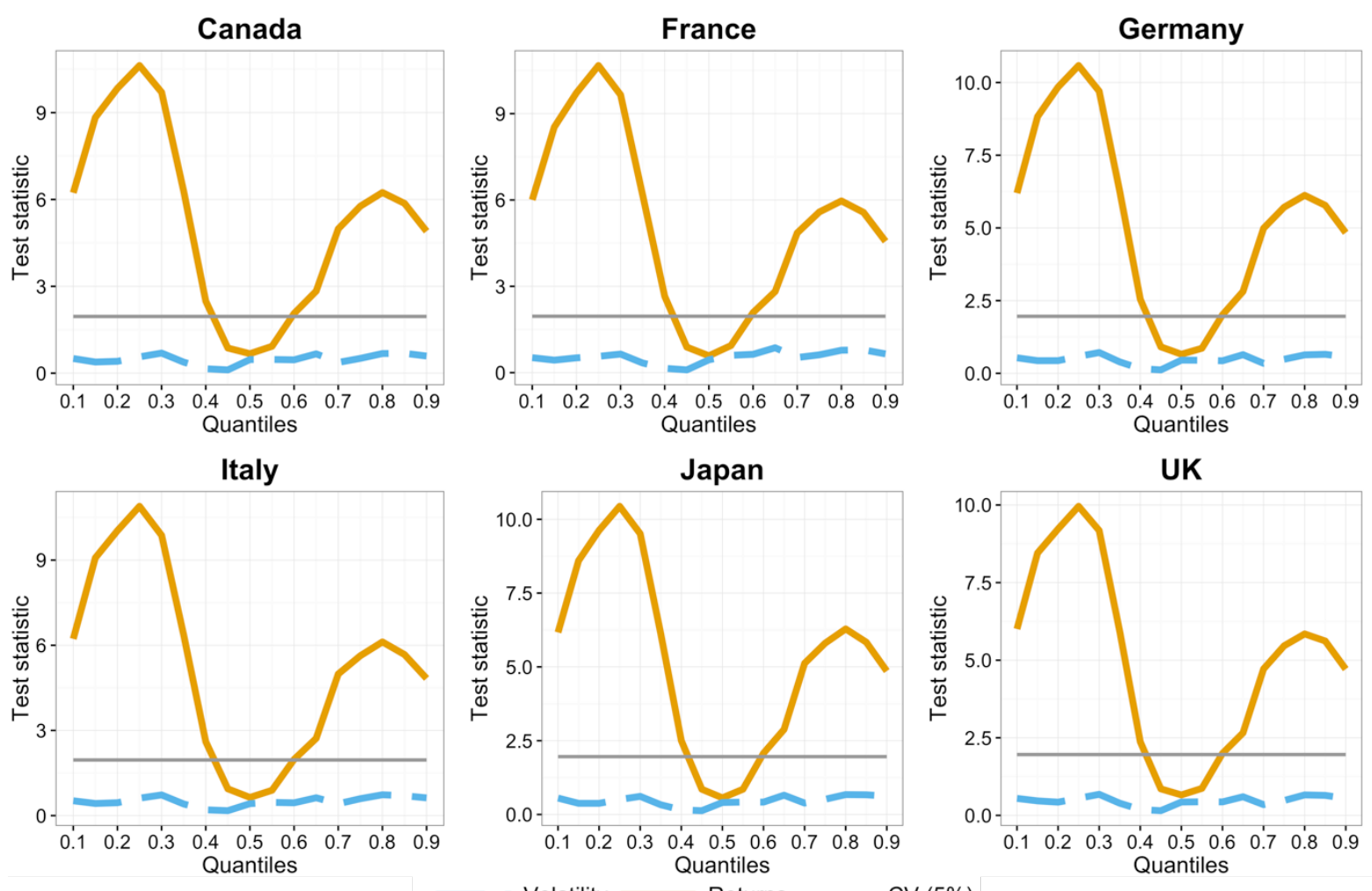